\title{
A 10-year analysis of organ donor referrals to a South African tertiary public sector hospital
}

\author{
T du Toit, ${ }^{1}$ MMed (Surg); K Manning, ${ }^{1}$ MSc (Med); D Thomson, ${ }^{1}$ MMed (Surg); F McCurdie, ${ }^{2}$ B Nursing; E Muller, ${ }^{1}$ PhD \\ ${ }^{1}$ Department of Surgery, Faculty of Health Sciences, University of Cape Town, and Groote Schuur Hospital, Cape Town, South Africa \\ ${ }^{2}$ Transplant Co-ordinator, Groote Schuur Hospital, Cape Town, South Africa
}

Corresponding author: Tdu Toit(dutoitjm@yahoo.com)

Background. South Africa (SA) has one of the lowest deceased organ donor rates in the world (1.4 donors per million population), with thousands of patients awaiting solid-organ transplantation. In order to improve access to transplantation we have to clearly define the reasons for the low deceased donation rate, specific to the population we serve.

Objectives. Review of actual donor statistics highlights our successes, yet is not able to contextualise the factors responsible for the unsuccessful conversion of referred organ donors to actual organ donors. In an attempt to identify key factors preventing referred donors from becoming actual donors, we analysed the donor referral patterns at our institution over a 10-year period.

Methods. This was a retrospective descriptive study of consecutive deceased donor referrals at Groote Schuur Hospital, Cape Town, SA (from January 2007 to December 2016), utilising a regional donor referral registry. Qualitative and quantitative data were collected and presented as descriptive statistics and temporal trends.

Results. Over the 10-year study period, 861 possible organ donors were referred, with a steady increase in the number of referrals over time. Of the referrals, 514 (59.7\%) were eligible for donation of at least one solid organ. Of the 508 families that were approached for consent to donation, 342 declined consent for a variety of reasons, resulting in a consent rate of $32.7 \%$. Ultimately, at least one solid organ was obtained from 159 of the 166 consented donors. Despite the increasing number of possible and eligible donors, a statistically significant decline in consent rate was observed over time $\left(p_{\text {trend }}=0.023\right)$. Furthermore, increasing trends in medical (as opposed to trauma) $\left(p_{\text {trend }}<0.001\right)$ and extended criteria (as opposed to standard criteria) donor referrals $\left(p_{\text {trend }}<0.001\right)$ were observed over the 10 -year study period.

Conclusions. Donor referral patterns have changed over time, with a notable increase in medical and extended criteria donors. Despite the increase in possible and eligible donors, the consent rate has declined. Further qualitative and quantitative research studies are required to understand and address this trend.

S Afr Med J 2020;110(2):132-134. https://doi.org/10.7196/SAMJ.2020.v110i2.14125

South Africa (SA) has one of the lowest deceased organ donor rates in the world (1.4 donors per million population), ${ }^{[1]}$ with thousands of patients awaiting solid-organ transplantation. ${ }^{[2]}$ Living donor (kidney and liver) transplant programmes have not been able to bridge the gap between organ supply and demand, and waiting lists continue to grow. In order to improve access to transplantation, we have to clearly define the reasons for the low deceased donation rate, specific to the population we serve.

Several reasons for the low donation rates in SA have been suggested. These include (but are not limited to) lack of central co-ordinating authority, limited legislation and regulatory guidelines regarding donor referral, religious and/or cultural concerns over deceased organ donation, and misconceptions regarding the donation process. ${ }^{[3-7]}$ In addition, we serve a diverse population with different sociocultural, sociopolitical and socioeconomic backgrounds. ${ }^{[8]}$ The discrepancy in healthcare resources between the public and private sectors results in a two-tiered healthcare system with unequal allocation of healthcare resources in our population. ${ }^{[9]}$ It would therefore be unwise to assume that the factors responsible for low donation rates in one geographical region or healthcare sector in SA are generalisable to another. With this in mind, we set out to identify the key factors in our referral system that prevented referred donors from becoming actual organ donors.

\section{Objectives}

The primary objective of the study was to identify key factors that prevented referred donors from becoming actual donors. The secondary objective was to describe the evolution of donor referral patterns by observing trends in number of referrals, donor demographics, cause of death, eligibility for solid-organ donation and consent rate over the 10-year study period.

\section{Methods}

This was a retrospective descriptive study of consecutive deceased donor referrals to Groote Schuur Hospital, Cape Town, over the 10-year period 1 January 2007 - 31 December 2016. All deceased donor referrals from public sector hospitals in the Northern, Eastern and Western Cape provinces were included (except for referrals from the Metro East drainage area of the Western Cape).

Descriptive statistics were used to summarise sample characteristics (including age, gender, cause of death, eligibility for donation and consent rates). Continuous variables were summarised as medians with interquartile ranges (IQRs). The $\chi^{2}$ test was used for categorical comparisons, while the $\chi^{2}$ test for trend was used to assess temporal trends over time. Analysis was performed in Stata 14 (StataCorp, USA). 


\section{Results}

Overview (Fig. 1)

Over the 10-year study period, 861 patients were referred to the on-call transplant co-ordinator at Groote Schuur Hospital. On initial assessment, 272 referrals (31.6\%) were deemed not medically suitable for solid-organ donation, and 514 referrals (59.7\%) were eligible for donation of at least one solid organ. Of the 508 families that were approached for consent to donation, 342 declined consent for a variety of reasons, resulting in a consent rate of $32.7 \%$. Ultimately, at least one solid organ was obtained from 159 of the 166 consented donors.

\section{Referred donors $(\boldsymbol{n}=\mathbf{8 6 1})$}

The 861 referrals mostly consisted of young (median (IQR) age 30 (21 - 43) years) men (74.1\%) who sustained non-survivable traumatic brain injuries (68.5\%); 179 (20.8\%) were referred for donation after circulatory death (DCD), and 85 (9.9\%) fulfilled criteria as extended criteria kidney donors (ECDs). Increasing trends in medical (compared with trauma) $\left(p_{\text {trend }}<0.001\right)$ and extended criteria (compared with standard criteria) donor referrals $\left(p_{\text {trend }}<0.001\right)$ were observed over the 10-year study period.

\section{Eligible donors $(n=514)$}

Referred donors were more likely to be assessed as eligible for solidorgan donation if they were referred from the trauma unit as opposed to the medical unit $(62.9 \%$ v. $52.8 \% ; p=0.005)$ and if they were candidates for donation after brain death (DBD) as opposed to DCD $(66.7 \%$ v. $33.0 \% ; p<0.001)$.

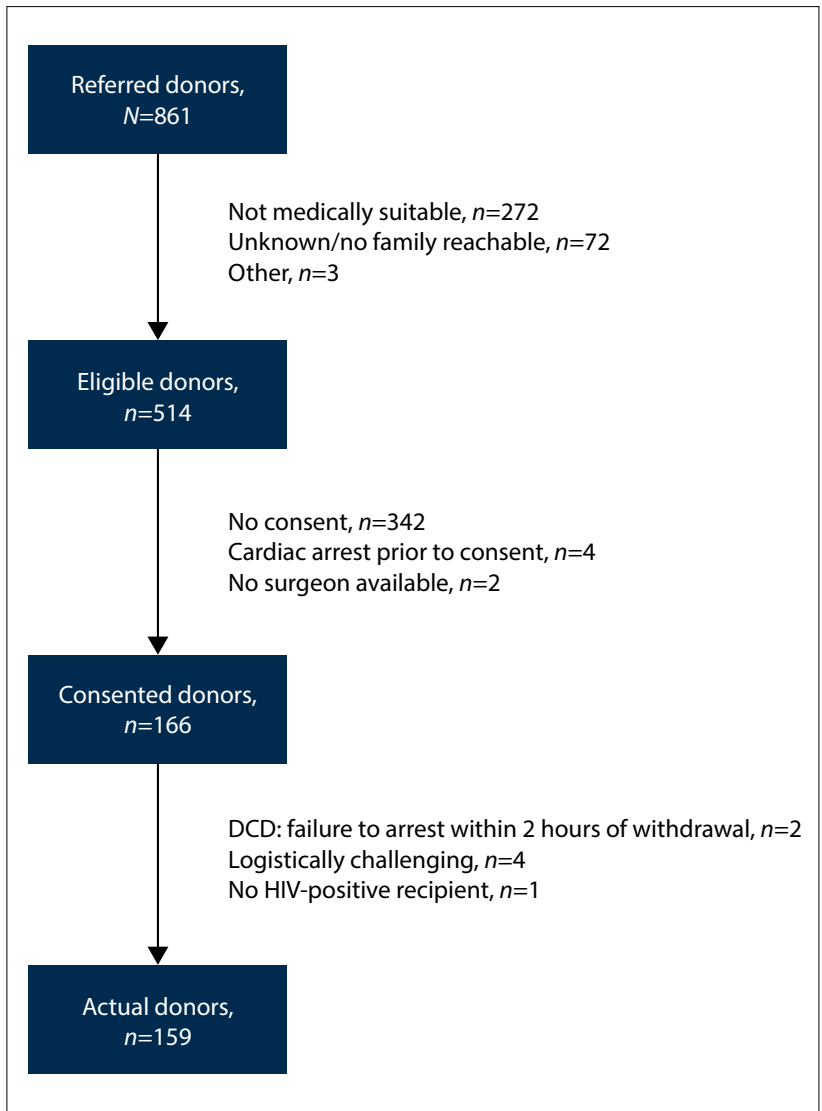

Fig. 1. Flow diagram highlighting the key factors that prevented referred donors from becoming actual donors. $(D C D=$ donation after circulatory death. $)$

\section{Consented donors $(n=166)$}

A significant decline in consent rate was observed over time $\left(p_{\text {trend }}=0.023\right)$. Subgroup analysis showed no significant difference in consent rates between medical and trauma ( 30.3 v. $33.4 \%$; $p=0.498$ ) or between DCD and DBD (25.9\% v. 33.4\%; $p=0.248)$ referrals. The total number of consented donors remained relatively constant over the 10-year period in spite of the decreasing consent rate owing to an increase in the number of referred and eligible donors (Fig. 2).

\section{Discussion}

In this study, only $20.3 \%$ of referred donors became actual donors. The three most common reasons were lack of medical suitability, lack of contactable family and consent refusal.

\section{Not medically suitable for donation $(n=272)$}

It is essential that the assessment of medical suitability of organs for transplantation be made by the relevant transplant teams. Waiting lists are dynamic, and urgent calls may exist where lessthan-perfect organs may offer a significant survival benefit over no transplant at all. Numerous studies have shown a clear survival benefit from transplantation with an ECD kidney compared with dialysis, resulting in a more liberal approach to deceased donor selection worldwide. ${ }^{[10-13]}$

In 2007, measures to expand the deceased kidney donor pool at our institution were implemented, including an HIV-positive-topositive transplant programme and the utilisation of ECDs as well as DCDs. In 2013, a deliberate attempt was made to increase the visibility of transplant co-ordinators in the trauma and casualty units by facilitating regular educational sessions with front-room medical staff and by attending daily ward rounds. During the study period, medical staff were encouraged to refer all possible donors to transplant co-ordinators for assessment, regardless of their apparent medical suitability for donation. This liberal referral policy is the reason for the increase in donor referrals over the study period (Fig. 2). It did, however, result in the exclusion of a large number of referrals (31.6\%), which were assessed as not medically suitable for donation.

In the UK, triggers for donor referral have been identified to ensure that all appropriate cases are considered for donation, and potential donor audits are conducted annually. In the USA, hospitals have federal funding linked to their support of the local organ

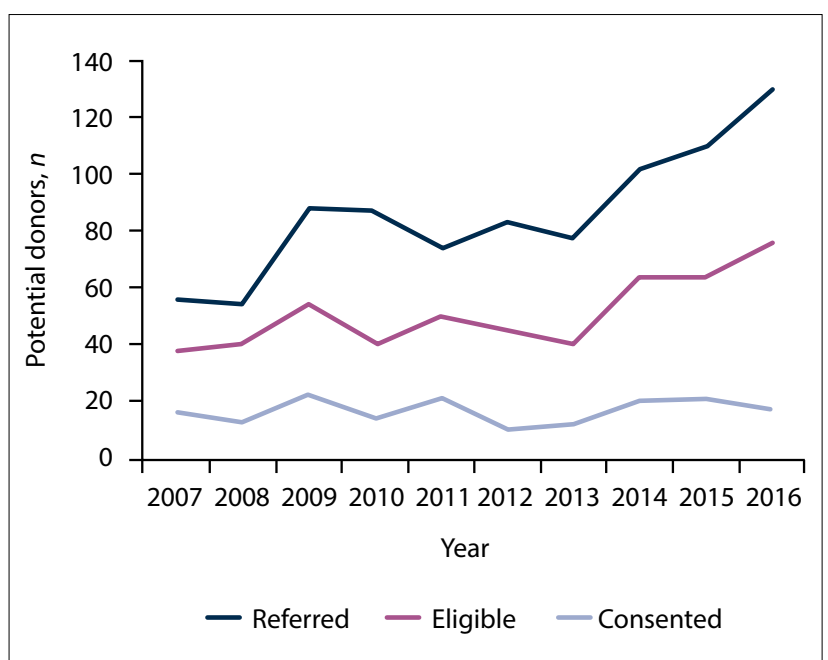

Fig. 2. Observed trends in the number of referred, eligible and consented donors over the study period. 
procurement organisation (OPO), which requires them to notify the OPO of all imminent deaths (prior to brain death certification or withdrawal of non-beneficial treatment).

Patient identity unknown/family not contactable $(\boldsymbol{n}=\mathbf{7 2})$ In $8.4 \%$ of referrals, either the identity of the patient was unknown or their family members/next of kin could not be contacted successfully. Although legally an unclaimed body is the property of the state, our organ procurement team does not proceed without consent from the next of kin. Owing to severe resource constraints, trauma/casualty resuscitation bays and intensive care unit beds are often at capacity in the public sector. Despite support from front-room staff, prolonged occupation of beds (while attempts are made to locate the family) is not justified in our setting, and pragmatic decisions in resource allocation have to be made.

\section{No consent granted by family/next of kin $(n=342)$}

Although an overall consent rate of $32.7 \%$ was achieved, a statistically significant decline in consent rate was observed over the study period. The reasons for not obtaining consent were not consistently documented in the donor referral registry and are often multifactorial. Anecdotally, most families refused consent on the basis of cultural/ religious objections to donation. Consent rates were similar in medical, trauma, DBD and DCD referral subgroups. A prospective study is currently underway at our institution to further investigate reasons for the low consent rate.

There is widespread recognition of the need to improve organ donation activity in SA. The current hospital-based system is fragmented, and various improvement initiatives are run by professional societies and local hospital groups. There is currently no co-ordinated national plan endorsed and supported by the government.

\section{Conclusions}

The donor referral landscape at our institution is changing, with a larger proportion of medical and extended criteria donors being referred. Despite an increase in referred and eligible donors, the consent rate has declined significantly over the past 10 years. Further qualitative and quantitative studies are required to understand and address this phenomenon. Government support is required to ensure appropriate monitoring and co-ordination of organ donation and transplantation in SA, to the benefit of the whole population.

\section{Declaration. None.}

Acknowledgements. None.

Author contributions. All authors made a substantial contribution to the conceptualisation and design of the study, and analysis and interpretation of data. All authors had the opportunity to approve the final version of the manuscript prior to submission.

Funding. None.

Conflicts of interest. None.

1. Moosa MR, Kidd M. The dangers of rationing dialysis treatment: The dilemma facing a developin country. Kidney Int 2006;70(6):1107-1111. https://doi.org/10.7196/SAMJ.2016.v106i2.9928

2. Organ Donor Foundation. Transplant statistics, 2016. https://www.odf.org.za (accessed 15 August 2017).

3. Bhengu B, Uys H. Organ donation and transplantation within the Zulu culture. Curationis 2004;27(3):24-33. https://doi.org/10.4102/curationis.v27i3.995

Pike RE, Odell J, Kahn D. Public attitudes to organ donation in South Africa. S Afr Med J 1993;83(2):91-94

5. Etheredge HR, Turner RE, Kahn D. Attitudes to organ donation among some urban South African populations remain unchanged: A cross-sectional study (1993 - 2013). S Afr Med J 2014;104(2):133populations remain unchanged: A cross-
137. https://doi.org/10.7196/SAMJ.7519

6. Naude A, Nel E, Uys H. Organ donation: Attitude and knowledge of nurses in South Africa. EDTNA 6. Naude A, Nel E, Uys H. Organ donation: Attitude and knowledge of nurses in
ERCA J 2002;28(1):44-48. https://doi.org/10.1111/j.1755-6686.2002.tb00198.x

7. Gidimisana ND. Knowledge and Attitudes of Undergraduate Nurses towards Organ Donation and Gidimisana ND. Knowledge and Attitudes of Undergraduate Nurses towards Organ Donation and
Transplantation in a Selected Campus of a College in the Eastern Cape. Cape Town: University of Cape Town, 2016. https://open.uct.ac.za/bitstream/handle/11427/21189/thesis_hsf_2016_gidimisana_ nozibele_dorothy.pdf?sequence $=1$ \&isAllowed $=y$ (accessed 15 August 2017)

8. Etheredge HR, Penn C, Watermeyer J. Interprofessional communication in organ transplantation in Gauteng Province, South Africa. S Afr Med J 2017;107(7):615-620. https://doi.org/10.7196/ SAMJ.2017.v107i7.12355

9. Mayosi BM, Benatar SR. Health and health care in South Africa -20 years after Mandela. N Engl J Med 2014;371(14):1344-1353. http://doi.org/10.1056/NEJMsr140501

10. Massie AB, Luo X, Chow EK, Alejo JL, Desai NM, Segev DL. Survival benefit of primary deceased donor transplantation with high KDPI kidneys. Am J Transplant 2014;14(10):2310-2316. https://doi org/10.1111/ajt.12830

11. Chow $\mathrm{EK}$, Massie $\mathrm{AB}$, Muzaale $\mathrm{AD}$, et al. Identifying appropriate recipients for $\mathrm{CDC}$ infectious risk donor kidneys. Am J Transplant 2013;13(5):1227-1234. https://doi.org/10.1111/ajt.12206

12. Merion RM, Ashby VB, Wolfe RA, et al. Deceased donor characteristics and the survival benefit of . Merion RM, Ashby VB, Wolfe RA, et al. Deceased donor characteristics and the survival ben
kidney transplantation. JAMA 2005;294:2726-2733. https://doi.org/10.1001/jama.294.21.2726

kidney transplantation. JAMA 2005;294:2726-2733. https://doi.org/10.1001/jama.294.21.2726
13. Stewart DE, Garcia VC, Rosendale JD, Klassen DK, Carrico BJ. Diagnosing the decades-long rise in Stewart DE, Garcia $\mathrm{VC}$, Rosendale JD, Klassen DK, Carrico BJ. Diagnosing the decades-long rise in
the deceased donor kidney discard rate in the United States. Transplantation 2017;101:575-587. https:// doi.org/10.1097/TP.0000000000001539

Accepted 2 July 2019 